\title{
THE NATURE OF VISCOSITY OF POLYVINYL ALCOHOL SOLUTIONS PACS 66.20.Cy, 61.25.he IN DIMETHYL SULFOXIDE AND WATER
}

\section{Introduction}

Liquid polyvinyl alcohol (PVA) solutions have a wide scope of applications. They are used in the textile and paper industries, cosmetics, agriculture, pharmacology, and medicine [1]. As a rule, water is the main solvent for PVA in chemical technology [1]. However, aqueous PVA solutions tend to the gelation: an irreversible growth of the viscosity in time is observed in concentrated aqueous PVA solutions [2]. Aqueous PVA solutions are widely applied in medicine as cryogels and polymer matrices for pharmaceutical dosage forms [3], as film-forming materials for the pellet coating, and as nutrient media [4]. They are used to encapsulate bacteria and are a component of membranes for the gas separation and dialysis [5]. The application of PVA in biology and medicine is associated with its ability to the biodegradation and the following excretion from organism [6].

(C) O.V. KHOROLSKYI, 2017

858
From the thermodynamic viewpoint [7], dimethyl sulfoxide $\left(\left(\mathrm{CH}_{3}\right)_{2} \mathrm{SO}, \mathrm{DMSO}\right)$ is a better solvent for PVA than water. This is an organic solvent that found applications in various domains of medicine (see, e.g., work [8]) due to its nontoxic actions on the human body. Therefore, researches of the physical properties of polyvinyl alcohol solutions in dimethyl sulfoxide and water are a challenging task for the physics of fluid systems, experimental medicine, and pharmacology.

The aim of this work is to study the physical nature of the shear viscosity in PVA solutions in water and DMSO. Relatively dilute solutions are considered, for which Einstein's formula for suspensions and its generalization can be used. More concentrated solutions, in which the interaction between macromolecules and the solvent reminds, in many respects, a solution of low-molecular liquids, will be studied separately, because, the required approach to the description of shear viscosity is absolutely different in this case.

ISSN 2071-0194. Ukr. J. Phys. 2017. Vol. 62, No. 10 


\section{Experimental Part}

Experimental researches of the concentration and temperature dependences of the kinematic viscosity and density of polyvinyl alcohol solutions in dimethyl sulfoxide and water were carried out in a temperature interval of 293-353 $\mathrm{K}$ and at PVA concentrations of $0.3,0.5,0.7,1,1.65,2.32,3,5,7$, and $10 \mathrm{wt} . \%$. The solution density was measured with an error of $0.05 \%$ using the pycnometric method. The kinematic viscosity was measured on capillary viscometers of the VPZh-2 type with an error of $2 \%$ using standard techniques.

For the researches, polyvinyl alcohol Mowiol 698 (Kuraray) with a hydrolysis degree of $98.4 \pm$ $\pm 0.4 \mathrm{~mol} . \%$ and without additional purification was used. As solvents, twice-distilled water and dimethyl sulfoxide $\left(\left(\mathrm{CH}_{3}\right)_{2} \mathrm{SO}\right)$ of the pharma grade were used. The latter was held on $\mathrm{NaOH}$ and distilled at a low pressure of $3-5 \mathrm{mmHg}$, with the middle fraction being collected. The solutions were prepared using the gravimetric technique. The solution concentration was calculated by the formula

$C=\frac{m_{\mathrm{PVA}}}{m_{\mathrm{PVA}}+m_{\mathrm{s}}} 100 \%$,

where $m_{\mathrm{PVA}}$ and $m_{\mathrm{S}}$ are the solute and solvent masses, respectively.

\section{Shear Viscosity in Relatively Dilute PVA Solutions}

In dilute solutions of flexible-chain polymers, isolated macromolecules exist in coil-like conformations [7]. In other words, with some reservations, macromolecular coils can approximately be regarded as spherical particles. According to the Einstein theory, in which a solute molecule is considered as a hard sphere and the solvent as a continuous medium [9], for the average viscosity of a solution of spherical particles, we have

$\bar{\eta}=\eta_{0}\left(1+\frac{5}{2} \varphi\right)$

where $\eta_{0}$ is the solvent viscosity, and $\varphi$ the volume concentration of macromolecular coils. The linear dependence of the shear viscosity on the volume concentration testifies to a negligibly low hydrodynamic interaction between the macromolecular coils.

However, as is known from work [9], formula (2) is only applicable at concentrations $\varphi<0.1$. With the growth of the solution concentration, the hydrodynamic interaction between the macromolecules becomes substantial. Batchelor [10] was the first who took this interaction into account and proposed the formula

$\bar{\eta}=\eta_{0}\left(1+\frac{5}{2} \varphi+5.2 \varphi^{2}+\ldots\right)$,

which generalized Einstein's one to volume concentrations $\varphi \leq 0.2$. Unfortunately, a further generalization of the Batchelor method faces considerable difficulties in determining the sum of the series and even in finding out whether the series converges or not.

In the recent years, there had been a number of works, in which particle-to-particle hydrodynamic interactions were taken into account and complemented with constructions borrowed from the researches of transport processes in dense molecular systems. The mutual influence of particles is described by an heuristic equation for the average values of the tensor of deformation rates in a suspension. As a result, the average viscosity of a suspension of spherical particles is determined by the relation [11]

$\bar{\eta}=\eta_{0}\left(1+\frac{5}{2} \frac{\varphi}{1-\varphi}\right)$.

Further progress in finding out the shear viscosity of more concentrated macromolecular solutions was attained due to the application of cellular models [11]. In those models, the perturbation of hydrodynamic fluxes by a particle in the suspension is assumed to be localized in a spherical cell that surrounds the particle. It is also supposed that the normal component of the perturbation velocity and the tangential stress equal zero at the cell boundary, which means the lack of friction at the external cell surface. In particular, in works [11-13], it was shown that the viscosity of a rather concentrated suspension is determined by the following relation, which is further referred to as the Malomuzh-Orlov formula:

$\bar{\eta}=\eta_{0} \frac{\psi(1-\psi)}{\psi(1-\psi)+1-\sqrt{1+2 \psi^{2}(1-\psi)}}$.

Here, $\eta_{0}$ is the solvent viscosity, $\bar{\eta}$ the average viscosity of the solution, $\psi=\left(R_{0} / R\right)^{3}, R_{0}$ is the radius of a particle in the suspension, and $R$ the cell radius. The 
asymptotics of $\bar{\eta}$ at $\psi \rightarrow 0$ and $\psi \rightarrow 1$ are

$\bar{\eta}= \begin{cases}\eta_{0}\left(1+\psi+\psi^{2}+\ldots\right), & \psi \rightarrow 0, \\ \frac{2}{3} \frac{\eta_{0}}{(1-\psi)}, & \psi \rightarrow 1 .\end{cases}$

Hence, the determination of the average suspension viscosity is reduced to the establishment of the relationship between the model parameter $\psi=\left(R_{0} / R\right)^{3}$ and the specific volume $\varphi=V_{0} / V$, where $V_{0}$ is the total volume occupied by particles in the suspension, and $V$ the volume of the system. The parameter $\varphi$ can be measured experimentally.

Note that the specific volume can also be determined using the formula [13]

$\varphi=\frac{4 \pi}{3} R_{0}^{3} / 8 R_{G}^{3}$

where $R_{G}$ has a meaning of the average distance between particles in the suspension. In work [13], it was shown that

$R=\left(\alpha_{0}+\alpha_{1} \varphi+\alpha_{2} \varphi^{2}+\ldots\right) R_{G}$,

where

$$
\begin{aligned}
& \alpha_{0}=\left(\frac{6}{2.5 \pi}\right)^{1 / 3}=0.93 \\
& \alpha_{1}=\frac{\pi \alpha_{0}^{4}}{18}\left(\left(\frac{6}{\pi \alpha_{0}^{3}}\right)-5.2\right)=0.127, \\
& \alpha_{2}=0.03 .
\end{aligned}
$$

Coefficients (9) were fitted to reproduce the series expansion (3) for dilute solutions. The cellular approach makes it possible to describe the behavior of the average suspension viscosity in the interval of volume macromolecule concentrations $\varphi \leq 0.5$. The upper limit actually coincides with the solution density, at which all macromolecules contact with one another $[12,13]$.

The described cellular approach for the determination of the average suspension viscosity was developed further in work [13]. Note also that the combination of the ideas implemented in the cellular approach and the representations of the activation mechanism of particle motion in liquids with nonspheric molecules brings about the heuristic formula [11]

$\bar{\eta}=\eta_{0} \exp \left(\frac{5}{2} \frac{\varphi}{1-\varphi}\right)$
For further calculations, it is important to discuss details of the calculation of the own macromolecule volume, as well as the boundary between dilute and concentrated solutions.

In order to estimate the applicability of relations (2)-(5) and (10) to the description of the concentration dependences of the shear viscosity in PVA solutions in water and DMSO, we have to change from the mass solution concentration to the volume concentration of macromolecular coils $\varphi$. They are evidently related to each other by the formula

$\varphi=\frac{4 \pi R^{3} \rho C N_{\mathrm{A}}}{3 M_{w}}$

where $R=R_{0} \sqrt{N}$ is the radius of a macromolecular coil (the average number of monomers in a PVA Mowiol 6-98 macromolecule amounts to $N=$ $=1000$ [14], and the minimum length of a monomer equals $R_{0}=2.5 \AA$ [15]), $\rho$ is the solution density, $N_{\mathrm{A}}$ the Avogadro constant, and $M_{w}$ the average molecular mass (for PVA Mowiol 6-98, $M_{w}=$ $=47000 \mathrm{~g} / \mathrm{mol}[14])$.

In the theory of dilute polymer solutions, the characteristic viscosity is used as a criterion for the estimation of the solution concentration mode [16]:

$[\eta]=\lim _{C \rightarrow 0}\left(\frac{\eta-\eta_{0}}{\eta_{0} C}\right)$

where $\eta$ is the viscosity of a polymer solution, $\eta_{0}$ the solvent viscosity, and $C$ the solution concentration in mass fraction units. A solution is called dilute, if the volume occupied by macromolecules is much smaller than the total solution volume.

With the growth of the polymer concentration, the solution structure changes from isolated macromolecules to their aggregates and, when achieving the critical concentration of macromolecular coil overlapping $C^{*}$ (the beginning of the so-called crossover region), to a network of intermolecular links. For flexible-chain polymers, the critical crossover concentration $C^{*}$ can be determined experimentally using the viscometric technique [16]:

$C^{*}=\frac{1}{[\eta]}$.

The analysis of the data in Table testifies that the transition from a dilute solution of polyvinyl alcohol in dimethyl sulfoxide to a semidilute one takes

ISSN 2071-0194. Ukr. J. Phys. 2017. Vol. 62, No. 10 


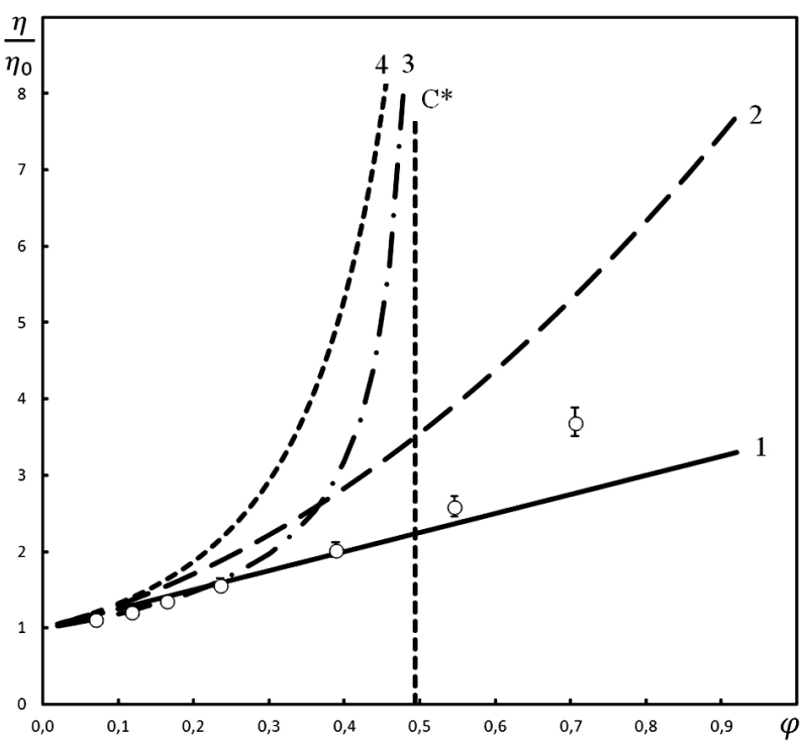

Fig. 1. Relative $\left(\bar{\eta} / \eta_{0}\right)$ experimental values for the shear viscosity in the aqueous PVA solution (circles) as a function of the volume concentration of macromolecules. Theoretical results: Einstein's formula (1), Batchelor's formula (2), MalomuzhOrlov formula (3), and formula (10) (4)

place at lower concentrations than in aqueous PVA solutions. In our opinion, this behavior results from the fact that the number of contact interactions between polyvinyl alcohol macromolecules is less than the corresponding number in the case of interactions between the PVA and solvent molecules [17].

Our experimental data and the data obtained by formulas (2)-(5) and (10) for the corresponding value of volume concentration $\varphi$ are presented in Figs. 1 and 2. From Fig. 1, it follows that, up to the concentration $\varphi \approx 0.6$, the experimental data agree with Einstein's formula (2). This result is puzzling, because the boundary between solutions, in which macromolecules are far from one another, and those, in which macromolecules begin to overlap is located at $\varphi=0.494$. In this connection, the assumption can be made that the size used by us for macromolecules, $R=R_{0} \sqrt{N}=79 \AA$, was significantly overestimated. In other words, in the aqueous PVA solution, the coils are significantly squeezed, so that their own volume considerably diminishes. This conclusion qualitatively agrees with a model of macromolecule consisting of a hard core and a rarefied periphery [18] that weakly affects the character of hydrodynamic perturbations.

ISSN 2071-0194. Ukr. J. Phys. 2017. Vol. 62, No. 10

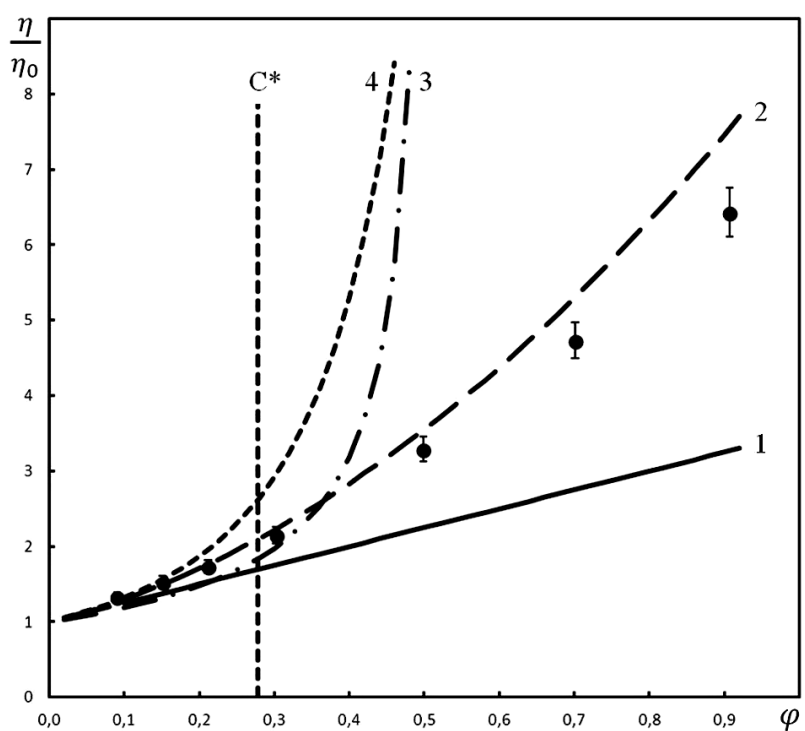

Fig. 2. The same as in Fig. 1, but for the PVA solution in DMSO

From Fig. 2, one can see that, for PVA solutions in DMSO with concentrations up to $\varphi \approx 0.75$, the experimental data agree with Batchelor's formula (3). The obtained data are contradictory, because this formula is only applicable for volume concentrations $\varphi \leq 0.2$. As was in the previous case, we may assume that the used size of macromolecules was not correct, and, as a result, the volume concentration of macromolecular coils was calculated erroneously.

Of the considered cellular approaches for the description of shear viscosity in diluted PVA solutions [Eqs. (2)-(5) and (10)], the Malomuzh-Orlov formula [Eq. (5)] is the most adequate one. It allows the behavior of the shear viscosity to be approximated up to the concentrations of macromolecular coil overlapping. Figures 3 and 4 demonstrate the corrected

Data for the characteristic viscosity $[\eta]$, average-viscosity molecular mass $M_{\eta}$, and critical crossover concentration in wt.\% $\left(C^{*}\right)$ and vol.\% $\left(\varphi^{*}\right)$ units of PVA solutions

\begin{tabular}{|l|c|c|c|c|}
\hline \multicolumn{1}{|c|}{ Solution } & $\begin{array}{l}{[\eta],} \\
\mathrm{dl} / \mathrm{g}\end{array}$ & $\begin{array}{c}M_{\eta}, \\
\mathrm{g} / \mathrm{mol}\end{array}$ & $\begin{array}{c}C^{*}, \\
\mathrm{wt} . \%\end{array}$ & $\begin{array}{c}\varphi^{*}, \\
\text { vol.\% }\end{array}$ \\
\hline $\begin{array}{l}\text { Polyvinyl alcohol } \\
\text { in dimethyl sulfoxide } \\
\begin{array}{l}\text { Polyvinyl alcohol } \\
\text { in water }\end{array}\end{array}$ & 1.09 & 38580 & 0.92 & 0.278 \\
\hline
\end{tabular}




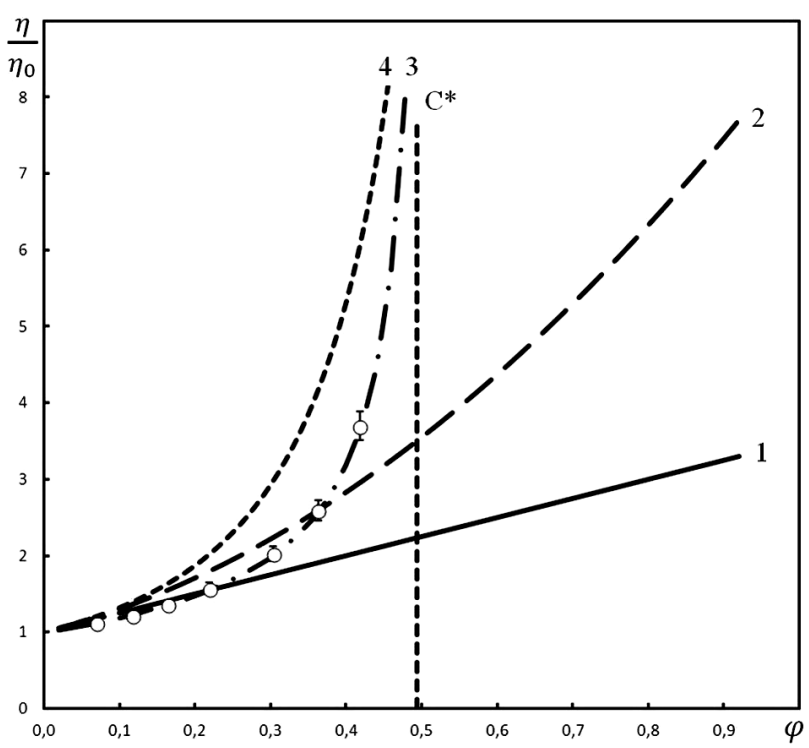

Fig. 3. Relative $\left(\bar{\eta} / \eta_{0}\right)$ experimental values for the shear viscosity in the aqueous PVA solution (circles) as a function of the corrected volume concentration of macromolecules. Theoretical results: Einstein's formula (1), Batchelor's formula (2), Malomuzh-Orlov formula (3), and formula (10) (4)

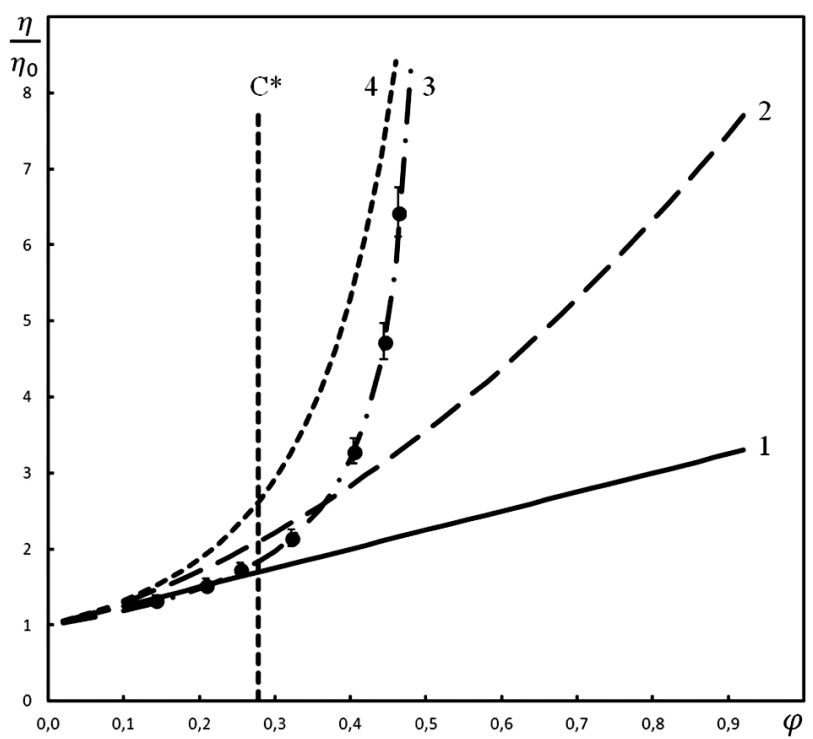

Fig. 4. The same as in Fig. 3, but for the PVA solution in DMSO

dependences of the relative shear viscosity $\bar{\eta} / \eta_{0}$ on the volume concentration of macromolecular coils $\varphi$, in which the variation of the effective macromolecule radius with the concentration growth was taken into account.

862

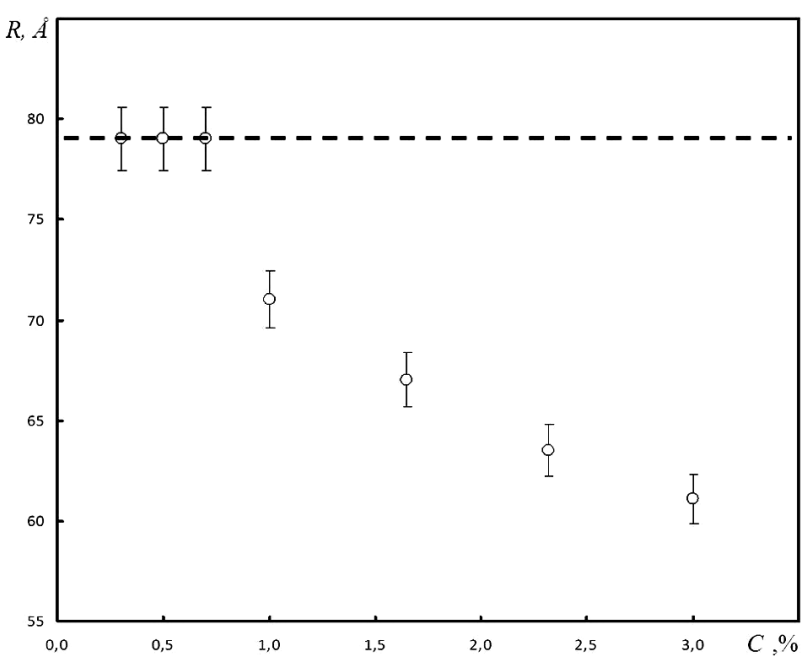

Fig. 5. Dependence of the effective radius of a macromolecular coil on the polyvinyl alcohol concentration in the aqueous solution. The dashed line marks the radius of a macromolecular coil determined by the formula $R=R_{0} \sqrt{N}=79 \AA$

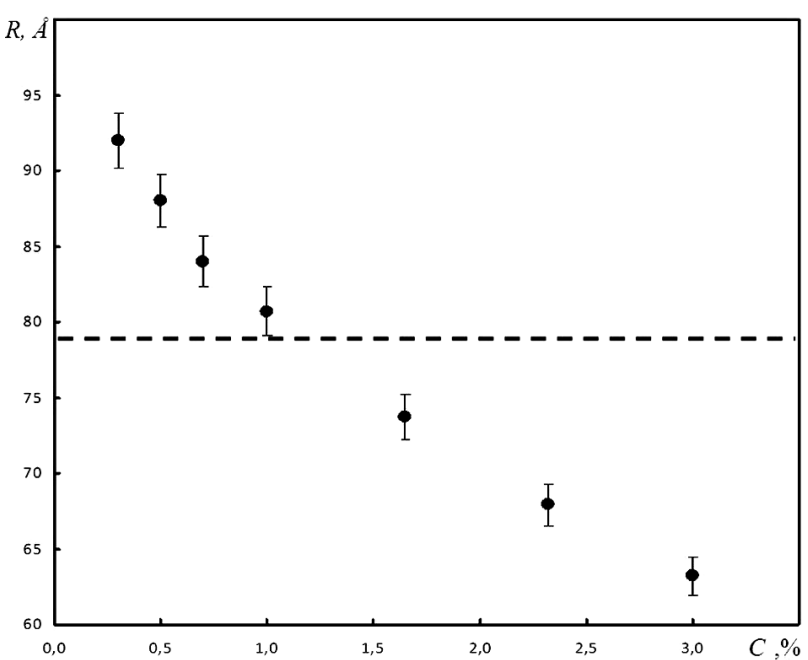

Fig. 6. The same as in Fig. 5, but for the PVA solution in DMSO

With the help of Malomuzh-Orlov formula (5) and Eqs. (7)-(9), in which the effective radius of a macromolecular coil enters implicitly, we obtain the concentration dependences for the effective radius of PVA macromolecular coils (Figs. 5 and 6). From Fig. 5, one can see that, in aqueous PVA solutions with concentrations lower than 1 wt.\%, the effective radius of a macromolecule remains invariant and is equal to $R=R_{0} \sqrt{N}=79 \AA$. At higher concentrations, this

ISSN 2071-0194. Ukr. J. Phys. 2017. Vol. 62, No. 10 
parameter decreases nonlinearly. At the same time, for PVA solutions in DMSO, the nonlinear descending dependence is observed in the whole concentration interval (Fig. 6), with the radii of macromolecular coils at low concentrations being, on average, by $15 \%$ larger than the predicted values, i.e. the effective radii of PVA macromolecular coils in dilute DMSO solutions are larger than in the aqueous solutions. This fact agree well with the conclusion of work [7] that DMSO is the best solvent for PVA from the thermodynamic viewpoint.

A similar behavior of the macromolecular coil size with the concentration growth was also observed in works $[19,20]$. This effect was assumed to be a result of the deformation of flexible-chain molecules owing to their mutual repulsion. In work [19], a nonlinear reduction of the specific volume of protein macromolecular coils with the growth of their concentration in aqueous solutions of polyethylene glycol $\left(M_{w}=8000 \mathrm{~g} / \mathrm{mol}\right)$ was demonstrated. A comparison of the experimental data with the data obtained by the simulation of a hard-sphere packing, revealed a tendency which is observed in Fig. 6. The authors of work [20] associated a reduction of the mean-square radius of macromolecules as the polymer concentration in the polyethylene glycol solution $\left(M_{w}=20000 \mathrm{~g} / \mathrm{mol}\right)$ grows with the folding of macromolecular coils owing to the interaction between them and their mutual penetration.

\section{Conclusions}

On the basis of experimental data, the applicability of the cellular approach to the description of the concentration dependences of the shear viscosity in aqueous and dimethyl-sulfoxide solutions of polyvinyl alcohol has been analyzed. It is shown that the Malomuzh-Orlov formula (5) allows the viscosity of polyvinyl alcohol solutions to be approximated by a function of the volume fraction of macromolecular coils in the solution, which is valid up to the concentrations of macromolecular coil overlapping. The model of a macromolecule consisting of a hard core and a rarefied periphery adequately describes the architecture of polyvinyl alcohol macromolecular coils in dimethyl sulfoxide and water in the case of dilute solutions.

In the framework of the Malomuzh-Orlov model theory, the concentration dependences are obtained for the effective radius of polyvinyl alcohol macromolecules in water and dimethyl sulfoxide. In both cases, the radius of polyvinyl alcohol macromolecular coils nonlinearly decreases with the growth of the PVA concentration. The effective radius of macromolecules is shown to be larger in the diluted solutions of polyvinyl alcohol in dimethyl sulfoxide than in water.

The author is sincerely grateful to Academician L.A. Bulavin for his permanent attention to the researches and the support of this work, as well as to Prof. M.P. Malomuzh and Prof. V.Ya. Gotsulskyi for their methodical help and detailed discussion of the results obtained.

1. R.O. Ebewele. Polymer Science and Technology (CRC Press, 2000) [ISBN: 0-0849-8939-9].

2. Yu.B. Mel'nichenko, L.A. Bulavin. Self-diffusion of water in gelatin gels: 2. Quasi-elastic neutron scattering data. Polymer 32, 3295 (1991).

3. A.K. Bajpai, S.K. Shukla, S. Bhanu, S. Kankane. Responsive polymers in controlled drug delivery. Prog. Polym. Sci. 33, 1088 (2008).

4. D.L. Deskins, Sh. Ardestani, P.P. Young. The polyvinyl alcohol sponge model implantation. J. Vis. Exp. 62, 3885 (2012).

5. A. López-Rubio, E. Sanchez, Y. Sanz, J.M. Lagaron. Encapsulation of living bifidobacteria in ultrathin $\mathrm{PVOH}$ electrospun fibers. Biomacromolecules 10, 2823 (2009).

6. F. Kawai, X. Hu. Biochemistry of microbial polyvinyl alcohol degradation. Appl. Microbiol. Biotechnol. 84, 227 (2009).

7. O.V. Khorolskyi, O.P. Rudenko. Viscometric research of concentration regimes for polyvinyl alcohol solutions. Ukr. J. Phys. 60, 880 (2015).

8. I.Yu. Kir'yanov, A.S. Barybin, V.A. Michalchenko. Application of dimethyl sulfoxide (DMSO) in experimental and clinical radiology. Med. Radiolog. 8, 73 (1976) (in Russian).

9. A. Einstein. Eine neue Bestimmung der Moleküldimensionen. Ann. Phys. 19, 289 (1906).

10. G.K. Batchelor. An Introduction to Fluid Dynamics (Cambridge Univ. Press, 2000) [ISBN 0-521-66396-2].

11. N.P. Malomuzh, E.V. Orlov. A new version of cellular method for the determination of suspension viscosity. Kolloid. Zh. 64, 802 (2002) (in Russian).

12. N.P. Malomuzh, E.V. Orlov. Static shear viscosity of a bimodal suspension. Ukr. J. Phys. 50, 618 (2005).

13. E.V. Orlov. Shear viscosity of dispersions of particles with liquid shells. Colloid J. 72, 820 (2010).

14. Mowiol Brochure en KSE (Kuraray Specialities Europe KSE GmbH, 2003).

15. R. Hasegawa, Y. Takahashi, Y. Chatani, H. Tadokoro. Crystal structure of the three crystalline forms of poly(vinylidene fluoride). Polym. J. 3, 600 (1972). 
16. C. Meng Kok, A. Rudin. A semi-empirical method for prediction of critical concentrations for polymer overlap in solution. Eur. Polym. J. 18, 363 (1982).

17. G. Tesei, G. Paradossi, E. Chiessi. Poly(vinyl alcohol) oligomer in dilute aqueous solution: a comparative molecular dynamics simulation study. J. Phys. Chem. B 116, 10008 (2012).

18. I.M. Lifshits, A.Yu. Grosberg, A.R. Khokhlov. Bulk interactions in the statistical physics of polymer macromolecule. Usp. Fiz. Nauk 127, 353 (1979) (in Russian).

19. S.B. Zimmerman, S.O. Trach. Estimation of macromolecule concentrations and excluded volume effects for the cytoplasm of Escherichia coli. J. Mol. Biol. 222, 599 (1991).

20. H.F. Abbasov, E.A. Masimov. Influence of potassium hydroxide on the formation of macromolecular coils in aqueous solutions of polyethylene glycol 20000. J. Qafqaz Univ. Phys. 4, 44 (2016).

Received 01.08.17. Translated from Ukrainian by O.I. Voitenko
О.В. Хорольсъкий

ПРИРОДА В'ЯЗКОСТІ РОЗЧИНІВ ПОЛІВІНІЛОВОГО СПИРТУ У ДИМЕТИЛСУЛЬФОКСИДІ ТА ВОДІ

$\mathrm{P}$ е $з$ ю м е

На основі експериментальних даних в'язкості розчинів полівінілового спирту в диметилсульфоксиді та воді аналізується застосовність коміркових підходів (формули Айнштайна, формули Бетчелора та їх узагальнень) до опису в'язкості розчинів від об'ємної концентрації макромолекулярних клубків. Показано, що з використанням моделі макромолекули, яка складається з твердого ядра та розрідженої периферії, формула Маломужа-Орлова адекватно описує в'язкість розчинів полівінілового спирту як функцію об'ємної частки макромолекулярних клубків у розчині аж до концентрації перекриття макромолекулярних клубків. Отримані концентраційні залежності ефективних радіусів макромолекул полівінілового спирту у воді та диметилсульфоксиді. Показано, що радіуси макромолекулярних клубків полівінілового спирту з ростом концентрації розчину нелінійно зменшуються. 